\title{
Respiratory issues in cancer survivors patients: Mini-review
}

\author{
Luis Mendoza* \\ *IQVIA Senior Medical Director, Medical Strategy \& Science, Oncology-Hematology Therapeutic Science \& Strategy \\ Unit,Czech Republic
}

Received: 8 December, 2017; Accepted: 19 December, 2017; Published: 27 December2017

*Corresponding author: Luis Mendoza, IQVIA, Senior Medical Director, Medical Strategy \& Science, Oncology-HematologyTherapeutic Science \& Strategy Unit, Czech Republic, Tel: +420 778700 845: E-mail:luis.mendoza@iqvia.com

\section{Introduction}

With the recent success of modern cancer therapy, cancer can be curable,and in cases where cure cannot be achieved, it can be treated as a chronic disease. As a result,there are now more than 15.5 million Americans with a history of cancer were alive on January 1, 2016. By January 1, 2026, this number is projected to reach 20.3 million [1]. These estimates do not include carcinoma in situ for any cancer except urinary bladder and do not include basal cell or squamous cell skin cancers. The respiratory effects of cancer therapy are critically important to the overall health of cancer survivors due to higher incidence of pulmonary disease compared with the general population. Because these conditions can result in a high degree of morbidity and mortality, understanding how to improve the prevention, recognition, and treatment of pulmonary disease is an important medical priority.

Cancer survivors are at increased risk for pulmonary disease that results from treatment with chemotherapy, immunotherapy and radiation therapy. This mini review paper will focus on the long-term respiratory and will also cover respiratory issues related to cancer therapy. These are reviewed below. Finally, practical recommendations will be made for certain principles that may help guide the optimal treatment of respiratory effects in cancer survivors.

\section{Pneumonitis}

Several chemotherapeutic agents are associated with interstitial pneumonitis, including bleomycin, cyclophosphamide, methotrexate, and carmustine. Of these, the pulmonary complications associated with bleomycin (an agent commonly used to treat Hodgkin lymphoma and testicular cancer) have been best characterized.

While this drug can cause a variety of insults, Bleomycin Interstitial Pneumonitis (BIP) is the most common. Depending on the definition used, BIP has been reported to occur in up to 46 percent of patients [2]. BIP is of particular relevance to the longterm care of cancer survivors, given its potential progression to pulmonary fibrosis and associated increased mortality. For example, a study of 38,907 survivors of testicular cancer treated with bleomycin in the past revealed an increased standardized mortality ratio of 2.53 (95\% CI 1.26-4.53) for respiratory diseases alone [3]. Late onset BIP typically develops more than six months after treatment $[4,5]$ presenting as a nonproductive cough, dyspnea, tachypnea, fever, and cyanosis. Radiographic imaging demonstrates variable findings but can show bilateral bibasilar infiltrate [2]. Patients with BIP tend to respond to corticosteroids $[4,6]$.

Pneumonitis can also occur with radiation therapy and typically occurs at least one to three months after completion of radiation therapy for lung, breast, esophageal cancers and bone metastases, Hodgkin and non-Hodgkin lymphoma, or total body irradiation for leukemia. The incidence and extent of radiation damage depends on the volume of lung irradiated, total radiation dose, and radiation fractions [7]. Again, common symptoms include dyspnea, hypoxia, nonproductive cough, and fever. Radiographic imaging tends to show changes confined to the outlines of radiation fields [7]. Steroids can be helpful and patients can have complete resolutionof symptoms after six to eight weeks of treatment. Like BIP, however, radiation pneumonitis can progress to fibrosis, making this particularly relevant to the care of long-term survivors.

\section{Immune-related pneumonitis}

Immune-checkpoint inhibitor therapy has emerged as a promising treatment option for advanced cancers[8-10]. Two PD-1 inhibitors have been approved by the U.S. Food and Drug Administration (FDA) for the clinical cancer treatment, including nivolumab for advanced melanoma, NSCLC, and RCC, and pembrolizumab for melanoma and NSCLC. A combination therapy using nivolumab and ipilimumab, a CTLA-4 inhibitor, has also been approved as a treatment for advanced melanoma $[11,12]$. Given the evidence for clinical efficacy in a wide spectrum of tumor types, PD-1 immune-checkpoint inhibitor therapy as monotherapy or in combination is projected to be increasingly used by oncologists. Immune-checkpoint blockade by PD-1 inhibitors is associated with unique toxicities,termed immunerelated adverse events (irAEs), which can involve different organs throughout the body [13-15]. Among the irAEs, pneumonitis is a relatively rare, but clinically serious and potentially life- 
threatening toxicity which might affect the quality of life specially those patients who achieve a durable response.Time from initiation of therapy to the development of pneumonitis had a wide range (0.5- 11.5 months), indicating an importance of careful observation and follow-up for signs and symptoms (i.e. cough and dyspnea) of pneumonitis throughout treatment. Shorter time to onset of pneumonitis in lung cancer compared to melanoma and lymphoma may be due to a higher pulmonary tumor burden among lung cancer patients, which can result in an earlier onset of respiratory symptoms. Immune-related pneumonitis showed a spectrum of radiographic patterns, which were associated with toxicity grades. The incidence of immunerelated mild/moderated pneumonitis is increased in patients who has previously received lung radiation therapy following the administration of durvalumab (PDL-1 inhibitor) as it was demonstrated in the Pacific trial [16].

Radiographic pattern of pneumonitis has a wide spectrum where the most frequently are the ground-glass opacities followed by cryptogenic organizing pneumonia, non-specific interstitial pneumonia, acute interstitial pneumonia/acute respiratory distress syndromeand hypersensitivity pneumonitis[17]. Most cases were responsive to corticosteroids and around one-third of the patients are able to restart therapy, though a few patients experienced recurrent pneumonitis during retreatment. These observations emphasize the importance of increased awareness of the entity for the early diagnosis and treatment.

\section{Fibrosis}

Pulmonary fibrosis is a dreaded complication of certain chemotherapies, including bleomycin, busulfan, and carmustine, and radiation treatment. In a small study of 17 children who received carmustine to treat brain neoplasms, 25-year follow-up revealed that nine (53 percent) died of pulmonary fibrosis. Of the eight survivors, follow-up was available on seven patients, who all showed signs of upper zone pulmonary fibrosis [18]. Radiation-induced pulmonary fibrosis develops at least 6 to 24 months after exposure to radiation, with patients presenting with progressive dyspnea and cough. In some cases, fibrosis is observed on imaging alone and patients are asymptomatic [19]. Steroids typically are associated with little benefit. The Childhood Cancer Survivor Study demonstrated that patients exposed to chest radiation were 4.3 times more likely than their siblings to have pulmonary fibrosis five years postdiagnosis.Chest radiation was also associated with a 3.5 percent cumulative incidence ofpulmonary fibrosis 20 years post-diagnosis [20].

\section{Bronchiolitis obliterans syndrome}

Pulmonary complications, specifically Bronchiolitis Obliterans Syndrome (BOS) and idiopathic pneumonia syndrome, are a significant source of morbidity and mortality in the Hematopoietic Stem Cell Transplantation (HSCT) population. Among 438 HSCT patients surviving more than three months, the incidence of late noninfectious pulmonary complications was 10 percent and the five-year survival rate of these patients was significantly lower compared with patients without pulmonary disease (34 versus 65 percent) [21]. BOS is a complication seen after allogeneic
HSCT and is observed in the presence of chronic graft-versus-host disease. This syndrome causes airflow obstruction secondary to progressive circumferential fibrosis with eventual scarring of terminal bronchioles [22]. It typically occurs within the first two years after transplant but can occur later, at four or five years. In 2005, the followingNational Institute of Health (NIH) diagnostic criteria were proposed: forced expiratory volume in one second (FEV) $<75$ percent predicted; FEV /forced vital capacity (FVC) ratio <0.7; evidence of air trapping, small airway thickening, or bronchiectasis on high-resolution computed tomography (HRCT) or residual volume (RV) >120 percent of predicted normal; and absence of respiratory tract infection or pathologic confirmation [23]. Using these criteria for BOS, a single center study of 1145 patients revealed a prevalence of 5.5 percent in transplanted patients and 14 percent in patients with chronic graft-versus-host disease [23]. However, International Bone Marrow Transplant registry data on 6275 adult patients with leukemia treated with allogenic HSCT reported an incidence of only 1.7 percent using prior diagnostic criteria [25].

In its early stages, patients are rarely symptomatic or have nonspecific symptoms of mild dyspnea on exertion or non-productive cough. However, as the disease progresses, patients suffer from significant dyspnea on exertion, persistent nonproductive cough, and decreased exercise tolerance. If BOS worsens, patients eventually develop significant hypoxia and become oxygen dependent, and alongside this an increased risk for pulmonary infections [26]. Diagnostic evaluation includes pulmonary function tests, HRCT, echocardiography to assess pulmonary artery pressures, infectious work-up, complete graft-versus-host evaluation, bronchoalveolar lavage, and tissue biopsy. Steroids are the mainstay of treatment, although their use has not beenevaluated in large clinical trials. Long-term survival is poor. Among 2859 bone marrow transplant patients, five-year survival of patients with BOS was 10 versus 40 percent in patients without BOS. In patients with BOS who responded to initial treatment with steroids, 79 percent survived at five years versus 13 percent ifthere was no response [27]. A 2011 consensus statement originating from the ConsensusConference on Clinical Practice in Chronic GVHD recommended routing pulmonary function testing screening in asymptomatic patients at 3, 6, 9, 12, 18 and 24 months after allogeneic stem cell transplantation and then annually[26].

\section{Idiopathic pneumonia syndrome}

Idiopathic pneumonia syndrome (IPS) includes a spectrum of noninfectious lung injury that carries a high mortality rate. In 2010, IPS was defined as an "idiopathic syndrome of pneumopathy after HSCT, with evidence of widespread alveolar injury and in which infectious etiologies and cardiac dysfunction, acute renal failure or iatrogenic fluid overload have been excluded"[28]. The median onset is considered to be six to seven weeks but more recently has been shown to occur as early as 19 days posttransplant (28), with an incidenceestimated to be on the order of 12 percent. Patients present with dyspnea, nonproductive cough, and hypoxemia, with non-lobar infiltrates are seen on radiographs [29].The syndrome typically leads to rapid respiratory failure and 
death. In 2003, Fukada et al reported a cumulative incidence of IPS of 2.2 percent in patients treated with non-myeloablative versus 8.4 percent in patients who underwent conventional conditioning prior to allogenic HSCT $(p=0.003)$ and a mortality rate of 75 percent [30].Etanercept, a TNF-alpha binding protein, has shown somebenefit in the treatment of these patients [31,32].

\section{Secondary lung cancer}

RT to the chest increases the risk of subsequent lung cancer. Among 64,782 breast cancer survivors who had surgery, at 10 to 14 years and $>15$ years from their initial diagnosis, patients who received radiation were at a significantly higher relative risk of lung cancer than those who did not (relative risk [RR] 1.62, 95\% CI 1.05-2.54 and RR 1.49, 95\% CI 1.05-2.14,respectively) [33]. Other populations who receive chest RT appear to also be at risk; in anotherstudy of survivors of Hodgkin lymphoma, those treated with chest RT had a relative risk of 2.7 to 7.0 of developing lung cancer [34].

\section{Monitoring pulmonary function and follow-up}

For patients suspected of having symptomsattributable to pulmonary toxicity, pulmonary function tests can be used to aid in the diagnosis ofsubclinical, asymptomatic disease.Despite the potential discrepancy between pulmonary function tests and overt clinical symptoms,early identification for pulmonary disease is important given it is a significant cause of mortality inadult survivors. In a Childhood Cancer Survivor Study which included 20,483 five-year survivors ofchildhood cancer, the cumulative mortality at 30 years from diagnosis was 18.1 percent (95\% CI,17.3-18.9) and survivors were 8.8 times more likely to die from a pulmonary cause [35].

\section{Summary}

In a study of 1713 survivors of childhood cancer, 65.2 percent (95\% CI 60.4-69.8) hadabnormal pulmonary function tests with the highest prevalence in those treated with lungradiation (74.4 percent [95\% CI 69.1-79.2], bleomycin (73.5 percent [95\% CI 61.9-82.9], andthoracotomy (53.2 [95\% CI 44.1-62.0]) [36]. In another study that included 220 five-year childhood cancer survivors who receivedpotentially pulmonary toxic chemotherapy, 44 percent had abnormal pulmonary function testsat a median follow-up of 18 years. Restrictive lung disease and decreased carbon monoxidediffusion capacity were the most common abnormality [37].

Long-term follow-up with spirometry and questionnaires of 1049 testicular cancer survivorsshowed that 8 percent had restrictive lung disease. In this study, patients treated with accumulative cisplatin dose greater than $850 \mathrm{mg}$ and patients treated with cisplatin andpulmonary surgery had increased odds of developing restrictive lung disease compared withpatients treated with surgery alone. Interestingly, of the patients diagnosed with restrictivelung disease, only 9.5 percent had selfreported dyspnea and 7.5 percent had prevalentasthma [38].

Pulmonary effects of chemotherapy, immune-check point inhibitors and chest radiation can have an insidious onset and devastating consequences. Providers should be aware of conditions that can present months or years after cancer treatment and are associated with increased bad quality of life and mortality.

Diagnostic evaluation can include pulmonary function tests, echocardiograms to assesspulmonary pressures, and chest radiographic imaging in patients who have been exposed to pulmonary toxic chemotherapy or chest radiation. Cancer survivors who continue to smoke tobacco should be counseled to discontinue tobacco use. Several studies have shown smoking increases the risk of a second malignancy $[39,40]$

\section{References}

1. Miller KD, Siegel RL, Lin CC, Mariotto AB, Kramer JL, Rowland JH, et al. Cancer treatment and survivorship statistic. CA Cancer J Clin. 2016 ;66(4):271-89.

2. Sleijfer S. Bleomycin-induced pneumonitis. Chest. 2001;120(2):617624.

3. Fosså SD, Gilbert E, Dores GM, Chen J, McGlynn KA, Schonfeld S, et al. Noncancer causes of death in survivors of testicular cancer. J Natl Cancer Inst. 2007;99(7):533-544. Doi: 10.1093/jnci/djk111

4. White DA, Stover DE. Severe bleomycin-induced pneumonitis. Clinical features and response to corticosteroids. Chest. 1984;86(5):723-728.

5. Uzel I, Ozguroglu M, Uzel B, Kaynak K, Demirhan O, Akman C, et al. Delayed onset bleomycin-induced pneumonitis. Urology. 2005;66(1):195. Doi: 10.1016/j.urology.2005.01.038

6. Maher J, Daly PA. Severe bleomycin lung toxicity: reversal with high dose corticosteroids. Thorax. 1994;48(1):92-94. Doi: 10.1136/ thx.48.1.92

7. Abid SH, Malhotra V, Perry MC. Radiation-induced and chemotherapyinduced pulmonary injury. CurrOpinOncol. 2001;13(4):242-248.

8. Brahmer JR, Drake CG, Wollner I, Powderly JD, Picus J, Sharfman WH, et al. Phase I study of single-agent anti-programmed death-1 (MDX-1106) in refractory solid tumors: safety, clinical activity, pharmacodynamics, and immunologic correlates. J Clin Oncol. 2010;28(19): 3167-3175. Doi: 10.1200/JC0.2009.26.7609

9. Suzanne L. Topalian, F. Stephen Hodi, Julie R. Brahmer, Scott N. Gettinger, David C. Smith, et al. Safety, activity, and immune correlates of anti-PD-1 antibody in cancer. N Engl J Med. 2012;366:2443-2454. Doi: 10.1056/NEJMoa1200690

10. Hodi FS, O’Day SJ, McDermott DF, Weber RW, Sosman JA, Haanen JB, et al. Improved survival with ipilimumab in patients with metastatic melanoma. N Engl J Med. 2010;363(13):711-723. Doi: 10.1056/ NEJMoa1003466

11. Jedd D. Wolchok, Harriet Kluger, Margaret K. Callahan, Michael A. Postow, Naiyer A. Rizvi, et al. Nivolumab plus ipilimumab in advanced melanoma. N Engl J Med. 2013;369:122-133. Doi:10.1056/ NEJMoa1302369

12. James Larkin, Vanna Chiarion-Sileni, Rene Gonzalez, Jean Jacques Grob, C. Lance Cowey, Christopher D. Lao, et al. Combined Nivolumab and Ipilimumab or Monotherapy in Untreated Melanoma. N Engl J Med. 2015;373:23-34. Doi: 10.1056/NEJMoa1504030

13. Michot JM, Bigenwald C, Champiat S, Collins M, Carbonnel F, PostelVinay S3, et al. Immune-related adverse events with immune checkpoint blockade: a comprehensive review. Eur J Cancer. 2016;54:139-148. Doi: 10.1016/j.ejca.2015 
14. Sree Harsha Tirumani, Nikhil H Ramaiya, Abhishek Keraliya, Nancy D Bailey, Patrick A Ott, F Stephen Hodi, and Mizuki Nishino, et al. Radiographic Profiling of Immune-Related Adverse Events in Advanced Melanoma Patients Treated with Ipilimumab. Cancer Immunol Res.2015;3:1185-1192.

15. Nishino M, Tirumani SH, Ramaiya NH, Hodi FS. Cancer immunotherapy and immunerelated response assessment: The role of radiologists in the new arena of cancer treatment. Eur J Radiol. 2015;84:1259-1268. Doi: 10.1016/j.ejrad.2015.03.017

16. Scott J. Antonia, Augusto Villegas, Davey Daniel, David Vicente, Shuji Murakami, Rina Hui. Durvalumab after Chemoradiotherapy in Stage III Non-Small-Cell Lung Cancer. N Engl J Med 2017; 377:1919-1929. Doi: 10.1056/NEJMoa1709937

17. Nishino M, Ramaiya NH, Awad MM, Sholl LM, Maattala JA, Taibi $\mathrm{M}$, et al. PD-1 inhibitor-related pneumonitis in advanced cancer patients: Radiographic patterns and clinical course. Clin Can Res. 2016;22(24):6051-6060. Doi: 10.1158/1078-0432.CCR-16-1320

18. Lohani S, O’Driscoll BR, Woodcock AA. 25-year study of lung fibrosis following carmustine therapy for brain tumor in childhood. Chest 2004;126(3):1007.Doi: 10.1378/chest.126.3.1007

19. Williams JP, Johnston CJ, Finkelstein JN. Treatment for radiationinduced pulmonary late effects: spoiled for choice or looking in the wrong direction? Curr Drug Targets. 2010;11:1386-1396.

20. Mertens AC, Yasui Y, Liu Y, Stovall M, Hutchinson R, Ginsberg J, et al. Pulmonary complications in survivors of childhood and adolescent cancer. A report from the Childhood Cancer Survivor Study. Cancer 2002;95(11):2431-2441. Doi: 10.1002/cncr.10978

21. Patriarca F, Skert C, Bonifazi F, Sperotto A, Fili C, Stanzani M, et al. Effect on survival of the development of late-onset noninfectious pulmonary complications after stem cell transplantation. Haematologica 2006;91(9):1268-1272.

22. Williams KM, Chien JW, Gladwin MT, Pavletic SZ. Bronchiolitis obliterans after allogeneic hematopoietic stem cell transplantation. JAMA 2009;302(3):306-314. Doi: 10.1001/jama.2009.1018

23. Filipovich AH, Weisdorf D, Pavletic S, Socie G, Wingard JR, Lee SJ, et al. National Institutes of Health consensus development project on criteria for clinical trials in chronic graft-versus-host disease: Diagnosis and staging working group report. Biol Blood Marrow Transplant. 2005;11:945. Doi: 10.1016/j.bbmt.2005.09.004

24. $\mathrm{Au} \mathrm{BK}, \mathrm{Au} \mathrm{MA}$, Chien JW. Bronchiolitis obliterans syndrome epidemiology after allogeneic hematopoietic cell transplantation. Biol Blood Marrow Transplant. 2011; 17(7):1072. Doi: 10.1016/j. bbmt.2010.11.018

25. Santo Tomas LH1, Loberiza FR Jr, Klein JP, Layde PM, Lipchik RJ, Rizzo JD, et al. Risk factors for bronchiolitis obliterans in allogeneic hematopoietic stem-cell transplantation for leukemia. Chest. 2005;128(1):153-161

26. Hildebrandt GC, Fazekas T, Lawitschka A, et al. Diagnosis and treatment of pulmonary chronic GVHD: report from the consensus conference on clinical practice in chronic GVHD. Bone Marrow Transplant. 2011;46:1283-1295. Doi: 10.1038/bmt.2011.35

27. Dudek AZ, Mahaseth H, DeFor TE, Weisdorf DJ. Bronchiolitis obliterans in chronic graftversus-host disease: analysis of risk factors and treatment outcomes. Biol Blood Marrow Transplant 2003;9(10):657666 Doi: $10.1016 /$ S1083
28. Panoskaltsis-Mortari A, Griese M, Madtes DK, Belperio JA, Haddad IY, Folz RJ, et al. An official American Thoracic Society research statement: noninfectious lung injury after hematopoietic stem cell transplantation: idiopathic pneumonia syndrome. Am J RespirCrit Care Med. 2011;183(9):1262-1279.

29. Clark JG, Hansen JA, Hertz MI, Parkman R, Jensen L, Peavy HH, et al. NHLBI workshop summary. Idiopathic pneumonia syndrome after bone marrow transplantation. Am Rev Respir Dis. 1993;147(6):16011606. Doi: 10.1164 /ajrccm/147.6_Pt_1.1601

30. Fukuda T, Hackman RC, Guthrie KA, Sandmaier BM, Boeckh M, Maris $\mathrm{MB}$, et al. Risks and outcomes of idiopathic pneumonia syndrome after nonmyeloablative and conventional conditioning regimens for allogeneic hematopoietic stem cell transplantation. Blood. 2003;102(8):2777-2785. Doi: 10.1182/blood-2003-05-1597

31. Yanik GA, Ho VT, Levine JE, White ES, Braun T, Antin JH. et al. The impact of soluble tumor necrosis factor receptor etanercept on the treatment of idiopathic pneumonia syndrome after allogeneic hematopoietic stem cell transplantation. Blood. 2008;112(8):30733081. Doi: 10.1182/blood-2008-03-143412

32. Tizon R, Frey N, Heitjan DF, Tan KS, Goldstein SC, Hexner EO, et al. Highdose corticosteroids with or without etanercept for the treatment of idiopathic pneumonia syndrome after allo-SCT. Bone Marrow Transplant. 2012;47(10):1332-1337. Doi: 10.1038/bmt.2011.260

33. Roychoudhuri R, Evans H, Robinson D, Møller H. Radiation-induced malignancies following radiotherapy for breast cancer. $\mathrm{Br} \mathrm{J}$ Cancer. 2004;91(5):868-872. Doi: 10.1038/sj.bjc.6602084

34. Lorigan P, Radford J, Howell A, Thatcher N. Lung cancer after treatment for Hodgkin's lymphoma: a systematic review. Lancet Oncol. 2005;6(10):773-779. Doi: 10.1016/S1470-2045(05)70387-9

35. Mulder RL, Thönissen NM, van der Pal HJ, Bresser P, Hanselaar W, Koning CC, et al. Pulmonary function impairment measured by pulmonary function tests in long-term survivors of childhood cancer. Thorax. 2011;66:1065-1071. Doi: 10.1136/thoraxjnl-2011-200618

36. Hudson MM, Ness KK, Gurney JG, Mulrooney DA, Chemaitilly W, Krull $\mathrm{KR}$, et al. Clinical ascertainment of health outcomes among adults treated for childhood cancer. JAMA. 2013;309(22):2371-2381. Doi: 10.1001/jama.2013.6296.

37. Armstrong GT, Liu Q, Yasui Y, Neglia JP, Leisenring W, Robison LL, et al. Late mortality among 5-year survivors of childhood cancer: a summary from the Childhood Cancer Survivor Study. J ClinOncol. 2009;27(14):2328. Doi: 10.1200/JC0.2008.21.1425

38. Haugnes HS, Aass N, Fosså SD, et al. Pulmonary function in longterm survivors of testicular cancer. J ClinOncol. 2009;27:2779. Doi: 10.1200/JCO.2008.18.5181

39. Ford MB, Sigurdson AJ, Petrulis ES, Ng CS, Kemp B, Cooksley C, et al. Effects of smoking and radiotherapy on lung carcinoma in breast carcinoma survivors. Cancer. 2003;98(7):1457-1464. Doi: 10.1002/ cncr.11669

40. Tabuchi T, Ito Y, Ioka A, Nakayama T, Miyashiro I, Tsukuma H. et al. Tobacco smoking and the risk of subsequent primary cancer among cancer survivors: a retrospective cohort study. Ann Oncol. 2013;24(10):2699-2704. Doi: 10.1093/annonc/mdt279 